\title{
ANALISIS SISTEM DAN PROSEDUR PEMBERIAN KREDIT USAHA RAKYAT DALAM UPAYA MENINGKATKAN PENGENDALIAN KREDIT PADA PT.BANK RAKYAT INDONESIA CABANG SANGSIT
}

\author{
Ni Luh Ayu Rosita Dewi \\ Jurusan Akuntansi Program Diploma III, \\ Universitas Pendidikan Ganesha, Singaraja
}

Ayurosita2015@gmail.com

\begin{abstract}
Abstrak
PT.Bank Rakyat Indonesia adalah satu lembaga keuangan milik pemerintah yang memberikan pelayanan kepada masyarakat dalam bentuk penyaluran kredit dan memberikan jasa-jasa lainnya dibidang keuangan. Dari hasil penyaluran kredit ini, bank akan memperoleh suatu keuntungan. Namun dalam realisasinya,penyaluran kredit oleh bank belum tentu berjalan dengan perjanjian,yang artinya masih ada kredit macet. Penelitian ini bertujuan untuk memperoleh jawaban dari suatu permasalahan yaitu untuk mengetahui Analisis Sistem dan Prosedur Pemberian Kredit Usaha Rakyat (KUR) pada PT. Bank Rakyat Indonesia.

Dalam penelitian yang dilakukan, jenis data yang digunakan dalah data kualitatif. Sumber data yang digunakan adalah data primer dan data sekunder. Semua data tersebut dikumpulkan dengan menggunakan metode wawancara dan dokumentasi. Teknis analisis data yang digunakan dalam penelitiaan ini adalah teknik analisis deskriptif kualitatif.

Berdasarkan penelitian tersebut, dapat disimpulkan bahwa analisis system dan prosedur pemberian kredit usaha rakyat pada PT.Bank Rakyat Indonesia dari tahapan permohonan,peminjaman,analisis kredit,pemberian keputusan kredit, perjanjian kredit dan pencarian kredit. Dokumen yang digunakan adallah formulir permohonan kredit, surat keterangan usaha dari kelurahan,formulir keputusan pencarian kredit. Bagian-bagian yang terlibat dalam pemberian kredit adalah bagian pemasaran, analisis kredit,pimpinan cabang, wakil pimpinan cabang, bagian hukum dan administrasi kredit dan Teller .
\end{abstract}

Kata kunci: sistem, prosedur, kredit KUR

PT.Bank Rakyat Indonesia is a government-owned financial institutions that provide services to the community in the form of loans and provides other services in the field of finance. From the results of this credit, the bank will gain an advantage. But the realization that lending by banks may not necessarily run with the agreement, which means there are bad credit. This study aimed to obtain answers from a problem is to know Analysis Systems and Procedures Giving People's Business Credit (KUR) at PT. Bank Rakyat Indonesia.

In a study conducted, the type of data used dalah qualitative data. Source data used are primary data and secondary data. All data were collected using interviews and documentation. Technical analysis of the data used in this penelitiaan is a qualitative descriptive analysis technique.

Based on these studies, it can be concluded that the analysis of systems and procedures providing small loans at PT.Bank Rakyat Indonesia on the stage of application, lending, credit analysis, decision granting credit, credit agreements and credit search. Documents used adallah credit application form, a letter from the village business, a decision form credit search. The parts involved in the provision of credit is a part of marketing, credit analysis, branch chief, deputy chief of the branch, the legal part and credit administration and Teller.

Keywords: systems, procedures, credit KUR 


\section{Pendahuluan}

Sebagai lembaga keuangan yang dibutuhkan masyarakat bank sangat membantu pemerintah dalam memperluas kesempatan kerja guna meningkatkan taraf hidup masyarakat, dengan produk kredit yang dimiliki. Perkembangan dunia usaha di Indonesia saat ini telah mengalami kemajuan yang sangat pesat terutama pada sektor Usaha Mikro Kecil dan Menengah karena pada saat ini telah banyak tumbuh pengusaha muda.

Banyak sekali bank di Indonesia yang masih menjadikan kredit sebagai salah satu sumber pendapatan utama yang diperoleh dari bunga yang dibebankan kepada debitur. Bank merupakan lembaga keuangan yang berfungsi menghimpun dana dari masyarakat dalam berbagai macam simpanan dan kemudian menyalurkannya kembali kepada masyarakat dalam berbagai jenis kredit.

Usaha Mikro Kecil dan Menengah merupakan salah satu pelaku ekonomi terbesar dalam perekonomian Indonesia dan terbukti menjadi sabuk pengaman perekonomian nasional dalam masa krisis, serta menjadi dinamisator pertumbuhan ekonomi pasca krisis ekonomi yang terjadi. Selain menjadi salah satu sektor usaha yang paling besar kontribusinya terhadap pembangunan nasional, UMKM juga menciptakan peluang kerja yang cukup besar bagi tenaga kerja dalam negeri, sehingga sangat membantu dalam upaya pemerintah mengurangi pengangguran.

Kredit usaha rakyat merupakan salah satu program pemerintah untuk membantu para pengusaha kecil agar dapat mengembangkan usahanya dengan menambah modal yang didapatkan dari pinjaman bank, dengan fasilitas kredit yang diberikan pada perusahaan atau perorangan diharapkan mereka mampu membiayai kebutuhan dana jangka pendek dalam rangka pembelian, perluasan dan pembaharuan.

Dalam pemberian Kredit Usaha Rakyat pada bank BRI dikaitkan dengan analisis kredit karena pada saat pemberian kredit pihak bank harus mengetahui itakad dari seorang debitur, kemampuan membayar pada debitur, kemampuan diri sendirinya, usaha debitur yang berpengaruh pada masa yang akan datang, dan nilai harta yang dijaminkan oleh seorang debitur,maka dari pihak bank harus melakukan survey sebelum menyetujui kredit yang diajukan oleh debitur.

Dengan adanya permasalahan seperti ini maka peneliti mengangkat judul tentang " Analisis Sistem dan Prosedur Pemberian Kredit Usaha Rakyat dalam Upaya Meningkatkan Pengendalian Kredit pada PT.Bank Rakyat Indonesia Cabang Sangsit".

\section{Metode Penelitian}

penelitian ini menggunakan analisis deskriptif kualitatif yaitu analisis yang tidak menggunakan perhitungan statiska dan dilakukan dengan cara menganalisis data yang sudah ada kemudian dioah menjadi sebuah teori. Melalui analisis ini dihrapkan dapat mengetahui Sistem dan Prosedur Pemberian Kredit Usaha Rakyat Dalam Upaya Meningkatkan Pengendalian Kredit pada PT Bank Rakyat Indonesia Cabang Sangsit. Agar tujuan penelitian ini dapat tercapai,maka peneliti melakukan pengumpulan data dengan metode wawancara dan dokumentasi. Penelitian ini dilakukan di PT Bank Rakyat Indonesia Cabang Sangsit yang beralamat di Jalan Raya Kloncing . Subjek penelitian ini adalah PT Bank Rakyat Indonesia Cabang Sangsit dan objek dari penelitian ini adalah Sistem dan Prosedur Pemberian Kredit Usaha Rakyat dalam Upaya Meningkatkan Pengendalian Kredit. Dari analisis yang dilakukan,langkah yang selanjutnya adalah penarikan kesimpulan dari analisis tersebut.Lokasi penelitian ini dilakukan di PT Bank Rakyat Indonesia Cabang Sangsit yang berlokasi di Jalan Raya Kloncing. Subjek dari penelitian ini adalah PT.Bank Rakyat Indonesia Cabang Sangsit. Dan objek penelitian ini adalah Sistem dan Prosedur Pemberian Kredit Usaha Rakyat dalam Upaya Meningkatkan Pengendalian Kredit. Jenis data yang digunakan adalah data kualitatif. Data kualitatif adalah data yang dinyatakan dalam bentuk kata, kalimat dan gambar. Data kualitatif yang digunakan seperti data-data permohonan kredit nasabah. Sumber data : 1)Data Primer Data primer adalah data yang diperoleh melalui wawancara langsung. Sebagai contoh adalah wawancara dengan analisis kredit di PT Bank Rakyat Indonesia Cabang Sangsit. 2) Data Sekunder,Data sekunder adalah data yang diperoleh dari objek penelitian itu sendiri, contohnya syarat-syarat permohonan kredit nasabah. Metode Pengumpulan Data :1)Wawancara Wawancara yaitu proses keterangan untuk tujuan peneliti dengan cara Tanya jawab sambil bertatap muka 
antara si penanya atau pewawancara dengan si penjawab atau perespon dengan menggunakan alat yang dinamakan panduan wawancara. Panduan wawancara yang digunakan adalah wawancara terstruktur dalam wawancara,pewawancara membawa pedoman yang merupakan garis besar tentng hal-hal yang akan ditanyakan. 2)Dokumentasi Dokumentasi yaitu dengan cara mempelajari catatan-catatan atau dokumen-dokumen perusahaan mengenai Pemberian Kredit Usaha Rakyat di PT Bank Rakyat Indonesia. Teknik Analisis Data Data yang telah terkumpul akan dianalisis dengan analisis deskriptif kualitatif. Analisis deskriptif kualitatif yaitu analisis yang tidak menggunakan perhitungan statiska dan dilakukan dengan cara menganalisis data yang sudah ada kemudian diolah menjadi sebuah teori. Metode ini menguraikan atau menggambarkan, memaparkan dan menjelaskan segala informasi yang didapat mengenai Sistem dan Prosedur Pemberian Kredit Usaha Rakyat Dalam Upaya Meningkatkan Pengendalian Kredit pada PT Bank Rakyat Indonesia Cabang Sangsit.

\section{Hasil dan Pembahasan}

\section{A. Sistem dan Prosedur Kredit Usaha Rakyat pada PT Bank Rakyat Indonesia Cabang Sangsit}

Sistem pemberian kredit usaha rakyat yang diterapkan pada PT Bank Rakyat Indonesia

Cabang Sangsit terdiri dari beberapa prosedur seperti prosedur pengajuan kredit, pemeriksaan berkas permohonan kredit, pemeriksaan jamianan sampai pada realisasi/pencairan kredit. Selain itu, prosedur pemberian kredit juga melibatkan beberapa bagian didalamnya, yaitu Bagian Kredit, Kepala Bagian Kredit,Wakil Pimpinan,Pimpinan Cabang, Bagian Hukum dan Administrasi Kredit dan Bagian Teller.

Prosedur pemberian kredit usaha rakyat pada PT BRI Cabang Sangsit sudah diterapkan dengan baik, dilihat dari langkah-langkah dalam prosedur pemberian kreditnya sudah sesuai dengan Bank dan Lembaga Keuangan lainnya. Prosedur pemberiaan kredit dimulai dari pengajuan berkas-berkas permohonan kredit, dalam hal ini debitur mengisi fomulir permohonan kredit dan melampirkan foto copy KTP suami dan istri, foto copy kartu keluarga,NPWP, kartu keluarga, buku tabungan,Surat keterangan usaha dari kelurahan. Selanjutnya adalah pengecekan kelengkapan permohonan kredit oleh analis kredit. Apabila data sudah lengkap maka akan dilanjutkan ketahap selanjutnya, akan tetapi apabila data belum lengkap maka nasabah diminta untuk melengkapi data permohonan sampai batas waktu yang ditentukan. Jika nasabah tidak bisa melengkapi data yang diperlukan maka permohonan kredit akan dibatalkan.

Setelah data lengkap maka akan dilakukan analisis dengan menggunakan analisis 5C, yaitu Character, Capasity, Capital, Collateral, Condition of Social and Economy Selain menggunakan analisis $5 \mathrm{C}$, analis kredit juga menggunakan analisis dengan menggunakan program komputer yang sudah diatur. Apabila angsuran kredit melebihi $50 \%$ maka permohonan kredit akan ditolak.

Setelah dilakukan analisis terhadap permohonan kredit selanjutnya adalah keputusan kredit. Keputusan kredit dalam hal ini adalah keputusan apakah permohonan kredit itu diterima atau di tolak. Apabila permohonan kredit diterima maka akan dipersiapkan administrasi oleh bagian Hukum dan Administrasi Kredit yang mencangkup jumlah kredit, jangka waktu kredit, tingkat suku bunga, biaya-biaya yang harus dibayar, jaminan dan lain-lain yang dianggap perlu. Sebelum kredit dicairkan debitur diwajibkan untuk menandatangani perjanjian kredit dan surat pengikatan jaminan. Selanjutnya adalah Tahap pencarian kredit Tahap pencarian kredit meliputi beberapa tahap yaitu tahap persiapan pencairan, penandatangan perjanjian pencairan kredit, fiat bayar dan pembayaran pencairan kredit.

PT BRI Cabang Sangsit sudah melaksanakan prosedur pemberian kredit sesuai dengan teori-teori yang ada. Selain itu prosedur pemberian kredit yang baik juga dapat mencerminkan sistem pemberian kredit yang baik juga. Hal itu karena sistem pemberian kredit terdiri dari prosedur-prosedur yang saling berhubungan satu dengan yang lainnya. 


\section{B. Pelaksanaan Sistem dan Prosedur Pemberian Kredit Usaha Rakyat dalam Upaya Meningkatkan Pengendalian Kredit}

Pelaksanaan sistem dan prosedur pemberian kredit usaha rakyat dalam upaya meningkatkan pengendalian kredit dapat dilihat dari beberapa aspek-aspek pengendalian kredit adalah sebagai berikut:

\section{Personal yang Kompeten dan Dapat Dipercaya}

Pengendalian kredit yang terjadi pada PT Bank Rakyat Indonesia untuk aspek ini berjalan dengan baik. Hal ini dibuktikan dari karyawan yang menangani kredit memiliki kemapuan yang memadai, serta adanya pelatihan untuk analis kredit pada saat-saat tetentu. Sehingga nasabah (calon debitur) bisa mendapatkan informasi secara benar.

2. Pemisahan Tugas yang Memadai

Pengendalian kredit yang terjadi yaitu adanya pemisahan tugas yang baik, sehingga prosedur pemberian kredit dapat berjalan sesuai teori yang ada. Pengendalian kredit sudah berjalan dengan baik, hal ini dibuktikan dari bagian-bagian yang menangani permohonan kredit berbeda mulai dari nasabah mengajukan kredit sampai pada pencairan kredit.

\section{Prosedur Otorisasi yang Tepat}

Pengendalian Kredit yang diterapkan oleh PT Bank Rakyat Indonesia telah mencerminkan pengendalian kredit yang baik, hal ini dapat dilihat bahwa proses kredit dapat dilakukan apabila syarat dan ketentuan dari pemohon kredit telah lengkap dan sesuai dengan prosedur kredit. Selain itu setelah analisis oleh analis kredit akan diuji kembali oleh Kepala Bagian Kredit, sehingga dapat mengurangi kredit yang bermasalah.

4. Dokumen dan Catatan yang Memadai

Pengendalian kredit atas dokumen dan catatan untuk setiap transaksi kredit yang direkam dalam sebuah formulir sudah mencerminkan pengendalian kredit yang baik. Hal ini dibuktikan dari adanya kelengkapan surat-surat perjanjian yang juga diketahui oleh notaris, selain itu juga adanya pengarsipan yang baik yang disesuaikan dengan nomor urut.

Secara keseluruhan sistem dan prosedur pemberian kredit usaha rakyat dalam upaya meningkatkan pengendalian kredit pada PT Bank Rakyat Indonesia mencerminkan atau menunjukkan pengendalian kredit yang baik, hal ini bisa dilihat dari 4 aspek yang diteliti.

\section{Simpulan dan Saran \\ 4.1 Simpulan}

Berdasarkan hasil penelitian dan pembahasan yang telah diuraikan pada bab sebelumnya, maka dapat disimpulkan sebagai berikut:

1. Sistem pemberian kredit usaha rakyat yang diterapkan pada PT BRI Cabang Sangsit terdiri dari beberapa prosedur seperti prosedur pengajuan kredit, pemeriksaan berkas permohonan kredit, pemeriksaan jaminan sampai pada realisasi/pencairan kredit. Prosedur Pemberian Kredit usaha rakyat (KUR) pada PT Bank Rakyat Indonesia Cabang Sangsit dimulai dari kedatangan nasabah (calon debitur) untuk mengajukan permohonan kredit, kemudian permohonan kredit dianalisis oleh bagian kredit dengan membuat MPK (Memorandum Pengusulan Kredit) dan diotorisasi oleh Kepala Bagian Kredit. Selanjutnya pemeriksaan jaminan oleh Wakil Pimpinan Cabang dan keputusan kredit oleh Pimpinan Cabang dengan membuat Surat Keputusan Kredit (SKK). Apabila kredit disetujui maka akan dibuatkan Surat Perjanjian Kredit (SPK) oleh Bagian Hukum dan Administrasi Kredit. Tahap terakhir adalah realisasi/pencairan kredit yang ditangani oleh Bagian Teller.

2. Pelaksanaan Sistem dan Prosedur Pemberian Kredit Usaha Rakyat (KUR) dalam Upaya Meningkatkan Pengendalian Kredit pada PT Bank Rakyat Indonesia Cabang Sangsit mencerminkan pengendalian kredit yang baik apabila dilihat dari aspek-aspek berikut ini :

1) Personal yang Kompeten dan Dapat Dipercaya

Pengendalian kredit yang terjadi mencerminkan pengendalian kredit yang baik. Hal ini dibuktikan dari adanya karyawan yang menangani kredit memiliki kemampuan yang memadai sehingga nasabah mendapatkan informasi secara benar.

2) Pemisahan Tugas yang Memadai

Pengendalian kredit pada aspek ini mencerminkan pengendalian kredit yang baik. Hal ini dibuktikan dari bagian-bagian yang menangani permohonan kredit berbeda mulai dari nasabah mengajukan kredit sampai pada pencairan kredit. 
3) Prosedur Otorisasi yang Tepat Pengendalian kredit pada aspek ini berjalan baik, hal ini dibuktikan dengan adanya proses pengujian kembali/otorisasi oleh Kepala Bagian Kredit.

4) Dokumen dan Catatan yang Memadai

Pengendalian kredit pada aspek ini mencerminkan pengendalian kredit yang baik, hal ini dibuktikan dari adanya kelengkapan surat-surat perjanjian kredit yang diketahui oleh notaris, selain itu juga adanya pengarsipan yang baik sesuai dengan nomor urut.

\section{DAFTAR PUSTAKA}

Adinugroho, R. Tjipto. 1994. Perbankan Masalah Perkreditan. Jakarta: Pradnya Paramita Azizah Rahman di 00.25 tentang Kredit Usaha Rakyat

Baridwan, Zaki. 1991. Sistem Akuntansi Penyusunan Prosedur dan Metode. BPFE Yogyakarta.

Christianto, Ivo Adi. 2013. Prosedur Pemberian Kredit dan Upaya Untuk mengatasi Kredit Macet pada Koperasi Kredit Swastiastu Singaraja. Singaraja: Akuntansi Program

Diploma III Fakultas Ekonomi dan Bisnis Undiksha.

https://www.cekaja.com/info/mengenal-kredit-usaha-rakyat/11.15

http://anasczr88.blogspot.co.id/2015/05/pengaruh-produk-kredit-usaharakyat.html http://www.bri.co.id/articles/9

https://id.wikipedia.org/wiki/Bank_Rakyat_Indonesia

Ismail.2011. Manajemen Perbankan.Jakarta : Kencana Prenada Media Group

Kasmir. 2004. Pemaasaran Bank. Jakarta:Prenada Media

Kasmir.2008. Bank dan Lembaga Keuangan Lainnya,Jakarta : PT Raja Grafindo Persada Kasmir. 2011. Manajemen Perbankan. Jakarta : PT Rajagrafindo Persada

Lapoliwa N,Kuswadi Daniel S.2000.Akuntansi Perbankan.Edisi ke-5 Jakarta: Institut Banker Indonesia

Mulyadi.2001. Sistem Akuntansi. Edisi ke-3. Bagian Penerbitan Sekolah Tinggi Ilmu Ekonomi YKPN Yogyakarta.

Mulyadi. 2010. Sistem Akuntansi. Edisi ke-5. Jakarta : Salemba Empat.

PT.Persero asuransi kredit Indonesia 7 Peb 2013 / 11.20

Sutarno.2004.Aspek-aspek Hukum Perkreditan Dan Bank Cetakan Ke-2 Bandung:Alfabeta CV

Suyatno,Thomas dkk. 1999. Dasar-dasar Perkreditan,Jakarta : PT Gramedia Pustaka Utama 